\title{
Short-term sick leave and future risk of sickness absence and unemployment - the impact of health status
}

\author{
Hanna Hultin ${ }^{1 *}$, Christina Lindholm², Mauricio Malfert ${ }^{3}$ and Jette Möller ${ }^{1}$
}

\begin{abstract}
Background: In previous studies the authors have found sick leave to be a predictor of future sick leave, unemployment and disability pension. Although sick leave reflects underlying health problems, some studies have suggested that sick leave may have consequences beyond the consequences of the underlying illness. However, few studies have aimed at studying consequences of sick leave while adjusting for ill health. This study aims to explore whether short-term sick leave increases the risk of future long-term sick leave, disability pension, and unemployment. Furthermore, we aim to control for the potentially confounding effects of physical and mental health status.

Methods: Data were gathered from the Stockholm Public Health Cohort (SPHC), restricted to 11,156 employed individuals (48.6\% men) aged 18-59, without long-term sick leave, disability pension or in-patient care the year before inclusion (2002). These were followed-up with regard to unemployment, long-term sick leave, and disability pension in 2006 and 2007.

Odds ratios (OR) with corresponding 95\% confidence intervals (Cl) were estimated by logistic regression, controlling for six different measures of health status (limiting long-standing illness, self-rated health, mental health, somatic disease, musculoskeletal pain and in-patient care) and socio-demographic factors.

Results: Results from the unadjusted analyses indicated increased risks of long-term sick leave (OR 2.00; Cl 1.62-2.46) and short-term unemployment (OR 1.76; $\mathrm{Cl} 1.35-2.29)$ for individuals exposed to more than one short-term sick-leave spell. There were no increased odds of long-term unemployment ( $\mathrm{OR} 0.54 ; \mathrm{Cl} 0.28-1.04$ ) or disability pension (OR 0.72; Cl 0.42-1.24). After adjusting for the different measures of health status the odds ratio for short-term unemployment was not statistically significant (OR 1.29; $\mathrm{Cl}$ 0.97-1.74). The odds ratios for the other outcomes slightly increased after adjustment for the used measures of health status.
\end{abstract}

Conclusions: The results support the assumption that short-term sick leave may have consequences for future sick leave beyond the effect of ill health. The results point to the importance of paying attention to short-term sick leave in order to prevent subsequent sickness absence.

Keywords: Short-term sick leave, Health status, Future sickness absence, Unemployment, Population-based study

\footnotetext{
* Correspondence: hanna.hultin@ki.se

${ }^{1}$ Department of Public Health Sciences, Karolinska Institutet, Stockholm, Sweden

Full list of author information is available at the end of the article
} 


\section{Background}

Sick leave is by definition absence from work due to illness, and sick leave is often used as an indicator of health [1-3]. In a number of studies, long-term sick leave has been shown to predict disability pension [4-17]. Studies of longterm sick leave have also indicated adverse financial and social effects, like a higher risk of unemployment and job termination [11,18,19]. A systematic review of factors associated with long-term sick leave concluded that there was only scientific evidence for an association with age and previous history of sick leave [20]. Additionally, age, sex, educational level, marital status, smoking, and adverse working conditions have been identified as risk factors for disability pension $[5,7,12,21-28]$.

A few studies have focused on short-term sick leave as a predictor of long-term sick leave or disability pension; for instance, the number of days and spells of sick leave have been shown to predict later sick leave and disability pension [29-31]. Although sick leave often is assumed to have consequences beyond the consequences of the underlying ill health, few studies have attempted to study the possible effect of sick leave while trying to adjust for the illness that it reflects [32,33]. In 2004, seven studies of the consequences of sick leave were scrutinized in a systematic review, but none of the included studies had controlled for ill health [33]. In 2009, an attempt to separate the consequences of sick leave from those of ill health was done using self-reports on the consequences of sick leave, specifically requesting the respondent to separate these from the consequences of disease/illness [32]. Despite the attempts, the authors indicated that there was uncertainty regarding to what degree the consequences studied could purely be attributed to sick leave. The possibility to study the effect of sick leave independently of health status increases when high quality data on ill health, before and during sick leave, is available.

In the present study we aim to explore whether shortterm sick leave (STSL) increases the risk of future longterm sick leave, disability pension, and unemployment. Furthermore, we aim to control for the potentially confounding effects of physical and mental health status.

\section{Methods}

This is a prospective cohort study based on data from the Stockholm Public Health Cohort (SPHC). The SPHC is based on random samples of the population of Stockholm County aged 18 to 84 years who participated in the Stockholm Public Health Surveys in both 2002 and a follow-up in 2007. In 2002 a total of 31,182 individuals responded to the baseline postal questionnaire (response rate $62.4 \%$ ) and in 2007 these were reassessed in a further health survey in which 23,794 participated (retention rate $76 \%)$. Information from Swedish health and administrative registers was linked using each citizen's personal identity numbers.

At the time of this study, all employees in Sweden were covered by the same sickness-benefit insurance, which after one qualifying day covered up to $80 \%$ of the income below a given limit, for full- or part-time sick leave. The first 14 days were financed by the employer, and thereafter by the Swedish National Social Insurance Agency. After seven sick-leave days, a medical certificate was required [34,35].

The study has been approved by The Regional Ethical Review Board in Stockholm and conforms to the principles of the Helsinki Declaration. All participants of the Stockholm Public Health Cohort have given informed written consent.

\section{Study sample}

For the purpose of this study we restricted the cohort to individuals $(48.6 \%$ men) aged $18-59$ in 2002. We excluded individuals who were unemployed, on full or part-time disability pension or on old-age pension in 2002. Furthermore, we excluded individuals who had more than 30 days sick-leave in 2001, or who had been admitted for in-patient care for more than three days or on more than three occasions in 2001. This resulted in final study sample of 11,156 individuals. Of the total 12,638 responders who were excluded from the study sample, $79.7 \%$ were due to either employment restrictions, age restrictions or a combination thereof.

\section{Exposure}

Information regarding short-term sick leave was assessed through the questionnaire in 2002 using the two questions; "Have you been on sick leave during the last 12 months?" (with response alternatives as 'No,' 'Yes, once, 'Yes, 2-4 times,' 'Yes, 5 times or more') and "How many days in total have you been on sick leave during the last 12 months?" (with response alternatives as 'Not absent', '1-7 days', '8-30 days', '31-90 days,' 'More than 90 days'). Exposure to high STSL was defined as those stating one of the following combinations: 'Yes, 2-4 times' and '1-7 days' in total; 'Yes, 5 times or more' and '1-7 days' in total; or 'Yes, 5 times or more' and '8-30 days' in total. Answering 'Yes, once' and '1-7 days' was defined as 1 short-term sick-leave spell, low STSL. Non-exposure was defined as answering 'No' and 'Not absent' to the two questions. Other combinations of responses were not included in the analyses, leaving a study group of 9844 individuals. Characteristics of these individuals are presented in Table 1.

\section{Outcomes}

Four outcomes were assessed; long-term sick leave, disability pension and short- and long-term unemployment. Longterm sick leave was defined as having more than 30 sick- 
Table 1 Characteristics of the study group in 2002 ( $n=9844), n(\%)$

\begin{tabular}{|c|c|c|c|c|c|}
\hline & & $\begin{array}{l}\text { Short-term sick-leave } \\
\text { (STSL) spells in } 2002\end{array}$ & & & \\
\hline & & No spell n (\%) & $\begin{array}{c}\text { Low STSL (1 spell) } \\
\text { n (\%) }\end{array}$ & $\begin{array}{c}\text { High STSL (>1 spell) } \\
\text { n (\%) }\end{array}$ & P-value* \\
\hline & Total & $4895(49.7)$ & $3125(31.8)$ & $1824(18.5)$ & \\
\hline \multirow[t]{2}{*}{ Sex } & Men & $2733(56.8)$ & $1430(29.3)$ & $714(14.6)$ & \\
\hline & Women & $2162(43.5)$ & $1695(34.1)$ & $1110(22.4)$ & $<0.0001$ \\
\hline \multirow[t]{3}{*}{ Age } & $18-29$ & $429(33.0)$ & $425(32.7)$ & $446(34.3)$ & \\
\hline & $30-44$ & $1828(45.0)$ & $1363(33.6)$ & $871(21.4)$ & \\
\hline & $45-59$ & $2638(58.9)$ & $1337(29.8)$ & $507(11.3)$ & $<0.0001$ \\
\hline \multirow[t]{5}{*}{ Socio-economic position 2002} & $\begin{array}{l}\text { Manual and skilled manual } \\
\text { worker }\end{array}$ & $953(44.8)$ & $697(32.8)$ & $477(22.4)$ & \\
\hline & Low non-manual workers & $554(43.4)$ & $447(35.0)$ & $277(21.7)$ & \\
\hline & $\begin{array}{l}\text { Middle and high non-manual } \\
\text { workers }\end{array}$ & $2549(48.4)$ & $1748(33.2)$ & $968(18.4)$ & \\
\hline & Self-employed and farmers & $741(73.3)$ & $189(18.7)$ & $81(8.0)$ & $<0.0001$ \\
\hline & Missing & 98 & 44 & 21 & \\
\hline \multirow[t]{3}{*}{ Born outside of Sweden } & Yes & $701(55.1)$ & $379(29.8)$ & $193(15.2)$ & \\
\hline & No & $4179(48.9)$ & $2738(32.1)$ & $1626(19.0)$ & $<0.0001$ \\
\hline & Missing & 15 & 8 & 5 & \\
\hline \multirow[t]{3}{*}{ Self-rated health } & Very good/Good & $4275(51.2)$ & $2652(31.8)$ & $1418(17.0)$ & \\
\hline & Fair/Bad/Nery bad & $579(41.1)$ & $446(31.6)$ & $385(27.3)$ & $<0.0001$ \\
\hline & Missing & 41 & 27 & 21 & \\
\hline \multirow{3}{*}{$\begin{array}{l}\text { Mental wellbeing measured } \\
\text { with GHQ } 12\end{array}$} & Yes to $<3$ items & $4103(51.9)$ & $2485(31.4)$ & $1315(16.6)$ & \\
\hline & Yes to $>=3$ items & $715(40.1)$ & $592(33.2)$ & $477(26.7)$ & $<0.0001$ \\
\hline & Missing & 77 & 48 & 32 & \\
\hline \multirow[t]{3}{*}{ Limiting longstanding illness } & $\begin{array}{l}\text { Yes, to a high degree/Yes, to } \\
\text { some degree }\end{array}$ & $399(43.6)$ & $264(28.8)$ & $253(27.6)$ & \\
\hline & No & $4459(50.4)$ & $2830(32.0)$ & $1555(17.6)$ & $<0.0001$ \\
\hline & Missing & 37 & 31 & 16 & \\
\hline
\end{tabular}

*P-values for Chi square tests.

leave days during 2007 and disability pension as the occurrence of full or part time disability pension in 2007. Both long-term sick leave and disability pension was measured by register data from the Swedish National Social Insurance Agency. Unemployment was assessed based on the number of reimbursed days from the unemployment insurance fund according to the longitudinal integration database for health insurance and labor market studies during 2006 (2007 not available). Short-term unemployment was defined as having 1-180 reimbursed days and long-term unemployment defined as having more than 180 reimbursed days.

\section{Confounders}

Information regarding potential socio-demographic and health-related confounders was retrieved from the 2002 survey and register data on country of birth and inpatient care in 2002. Age was categorized into three groups: 18-29, 30-44 and 45-59 years, and the youngest group were used as reference category. Socio-economic status (SES) was measured through a question on the respondent's occupation and classified in accordance with Statistics Sweden classification [36]. For the analyses each participant was allocated to one of the following four socio-economic groups: Higher and intermediate nonmanual employees, lower non-manual employees, manual workers (skilled and unskilled), and self-employed (selfemployed and farmers). In the analyses the lower nonmanual employees were used as the reference group. Other measures of socio-economic position, such as income and education, were also tested. Country of birth was based on a survey question, dichotomised as born in Sweden or elsewhere.

Self-rated health (SRH) was measured by one survey question with five response alternatives, varying from 
very bad to very good. Adverse self-rated health was defined as response alternatives; 'very bad,' 'bad' and 'fair' $[37,38]$. Limiting longstanding illness (LLSI) was based on two questions; "Do you have a long-standing illness, ailment due to an accident, handicap or other weakness?" with response alternatives 'yes' or 'no' and if yes, the respondent answered a supplementary question if this longstanding illness causes a reduced work capacity or limits one's other daily activities to a great extent, to some extent or not at all. LLSI was defined as having a longstanding illness that limited the work capacity or other activities to at least some extent. Mental health status was assessed using the General Health Questionnaire 12 (GHQ-12) which was included in the survey [39]. The 12 items of the GHQ-12 measure interruptions to normal function rather than life-long characteristics and are designed to capture mental reactions to strains. Each question is scored 0 for good mental well-being or 1 for poor, giving a maximum of 12 points and a minimum of 0 . A summary score of three and above was considered as decreased mental wellbeing. It has been validated for use in the Swedish population and a score of three and above is used in Sweden to denote significantly decreased mental wellbeing [40]. Somatic disease was a combined measure including five diseases available in the survey questions about whether the respondent ever had been diagnosed for any of these by a physician: diabetes, angina pectoris, myocardial infarction, heart failure or cerebral haemorrhage. Musculoskeletal pain was created by combining three survey questions regarding the presence of pain in the neck or upper back, the lower back and shoulders or arms during the previous six months. Respondents who reported pain in either of these body parts "a couple of days a month" or more often were considered as having musculoskeletal pain. The sixth measure was in-patient care during the year of exposure (2002) based on information from the National Patient Registry.

\section{Statistical analyses}

Descriptive analyses of background factors and potential confounders were computed from frequencies, and the differences were tested with Chi-square tests with associated p-values.

The odds ratios (OR) with corresponding 95\% confidence intervals $(\mathrm{CI})$ were obtained using logistic regression in order to model the effect of STSL on the risk of future long-term sick leave, disability pension, and short- and long-term unemployment. In the analyses, the effect was adjusted for the confounders in eight multivariate regression models.

Variables derived from the population-based registers did not yield any partially missing values. In the surveys there were some partially missing answers, ranging from $0.3 \%$ for country of birth to $1.7 \%$ for socio-economic status; hence the number of individuals included in the different models differs slightly. Excluding all individuals with partially missing answers $(n=550,5.6 \%)$, basing the analyses solely on those with complete information on all variables, did not alter the effect estimates.

All statistical analyses were performed using the SAS statistical software, version 9.2 (SAS Institute Inc., Cary, NC, USA).

\section{Results}

A total of $31.8 \%$ of the participants, reported low STSL during the last 12 months in 2002, and 18.5\% reported high STSL during the same period (Table 1). There were statistically significant differences between sex and age groups in the prevalence of STSL. Among women 22.4\% reported high STSL, compared to $14.6 \%$ among men, and among 18-29 year olds, 34.3\% reported high STSL compared to $21.4 \%$ and $11.3 \%$ in the older age groups. Prevalence differences were also detected between socioeconomic groups, $8.0 \%$ of self-employed individuals reported high STSL compared to $18-22 \%$ among other socio-economic groups. Among those with less than good self-rated health, $27.3 \%$ reported high STSL, compared to $17.0 \%$ among the others. Similarly, $26.7 \%$ of individuals with decreased mental wellbeing reported high STSL, compared to $16.7 \%$ among those with good mental wellbeing.

In Table 2, differences in the number and percentage of the outcomes 2006-2007 is shown, stratified on STSL.

Table 2 Short-term sick leave (STSL) in 2002, number and percentage of the outcomes, in 2006-2007

\begin{tabular}{|c|c|c|c|c|c|c|c|c|c|c|c|c|}
\hline \multirow[t]{3}{*}{ Short term sick leave (STSL) in 2002} & \multicolumn{12}{|c|}{ Outcome measures } \\
\hline & \multicolumn{3}{|c|}{$\begin{array}{c}\text { Sick leave more than } 30 \\
\text { days in } 2007\end{array}$} & \multicolumn{3}{|c|}{$\begin{array}{l}\text { Disability pension in } \\
2007\end{array}$} & \multicolumn{3}{|c|}{$\begin{array}{c}\text { Unemployment in } 2006 \\
\leq 180 \text { days }\end{array}$} & \multicolumn{3}{|c|}{$\begin{array}{c}\text { Unemployment in } 200 \\
>180 \text { days }\end{array}$} \\
\hline & n & $\%$ & p-value* & $\mathrm{n}$ & $\%$ & p-value* & n & $\%$ & p-value* & $\mathrm{n}$ & $\%$ & p-value* \\
\hline High STSL (> 1 spell) $n=1824$ & 160 & 8.8 & $<0.0001$ & 17 & 0.9 & 0.2377 & 94 & 5.2 & $<.0001$ & 11 & 0.6 & 0.1063 \\
\hline Low STSL (1 spell) $n=3125$ & 197 & 6.3 & & 29 & 0.9 & & 103 & 3.3 & & 38 & 1.2 & \\
\hline No STSL $n=4895$ & 225 & 4.6 & & 63 & 1.3 & & 146 & 3.0 & & 54 & 1.1 & \\
\hline Missing & 0 & & & 0 & & & 127 & & & 0 & & \\
\hline
\end{tabular}

*P-value for Chi-square tests. 
Among those exposed to high STSL, 8.8\% had long-term sick leave in 2007 , compared to $4.6 \%$ among those with no STSL. There were similar differences between exposure groups in the prevalence of short-term unemployment in 2006, although the general prevalence figures were slightly lower. There were no statistically significant differences in the prevalence of disability pension in 2007 or long-term unemployment in 2006 between the exposure groups.

Table 3 shows statistically significant higher crude odds ratios for long-term sick leave and short-term unemployment among those exposed to high STSL, and a significant higher odds ratio for long-term sick leave for those exposed to low STSL. No increased odds ratios were found for short-term unemployment for individuals exposed to low STSL. No increased odds ratios were found for long-term unemployment and disability pension. Overall, adjustment for all measures of health status in 2002 and socio-demographic factors only slightly changed the estimates. After these adjustments the odds ratio of future long-term sickness absence for those with high STSL was 2.11 (95\% CI 1.67-2.67). The odds of long-term sick leave appeared to increase with increasing exposure. There was a crude increased odds of short-term unemployment among those exposed to high STSL, but after adjustment for mental wellbeing and sociodemographic factors, the effect estimates were not statistically significant (OR 1.25 95\% CI $0.93-1.67$ ). After adjustments for confounding no statistically significant effect of STSL was found on either longterm unemployment (OR $0.56 \quad(95 \% \quad 0.26-1.18)$ or disability pension (OR 0.74 95\% 0.42-1.33).

\section{Discussion}

Having high STSL in 2002 increased the odds of future long-term sick leave in 2007. The increased odds of long-term sick leave remained after adjustment for socio-demographic factors and self-reported health status and register data on in-patient care from 2002. The results did not support STSL (high or low) to be a substantial risk factor for adverse labor market position. Exposure to STSL implied no statistically significant increased risks of unemployment or disability pension after adjustment for health status and sociodemographic factors.

Studies on the consequences of short-term sickness absence are scarce; however, our results are in line with those published $[11,18]$. These studies showed that frequent short-term absence was a predictor for later long-term sickness absence [18] and that sickness absence of more than 15 days per year was a risk factor for terminated employment, mainly resulting in unemployment $[11,29]$. In our study, we found an increased risk of long-term sick leave among individuals with STSL. The OR of short-term unemployment was above one but not statistically significant after adjustment for all measures of health status. Few of these previous studies had the possibility to control for health status. The differences between our study and previous studies, regarding the risk of unemployment, could be due to the differences in exposure definitions or due to the fact that the association previously found between sick leave and unemployment mainly is due to the ill health that sick leave reflects.

Another study showed that the duration of sick-leave spells and the total number of sick-leave days in a year were the strongest predictors of disability pension, which led the researchers to conclude that the pathway to disability pension starts with short term sick-leave periods, then increasing in length until the disability pension [31]. Our findings show that STSL increased the odds of longterm sick leave, but not of disability pension. However, it is important to note that our study investigated an initially healthy cohort, and it is likely that it may take longer than the five-year follow up to transition from short-term sickness absentee, to long-term sickness absentee to disability pensioner. The time period from short-term to long-term sick leave and later exclusion from the labor market may depend on severity of disease and type of work load but we have not found any studies regarding this issue.

\section{Strengths and limitations}

The strength of this study is firstly the longitudinal design and the large number of participants, and secondly the opportunity to combine survey data and register data, available from 2001 until 2007. This allowed us to limit the sample by excluding persons with long-term sick leave and in-patient care in 2001 and thereby avoid short-term STSL in 2002 being a continuation of previous severe illness [41].

In order examine the consequences of sick leave when controlling for health status, we used our access to selfreported health assessments in the survey from 2002. This captured different aspects of general health measured by SRH, GHQ-12, and LLSI. The GHQ-12 questionnaire is a well-established and validated instrument, measuring mental well-being [41]. Further, the questions covering long-term limiting illness and musculoskeletal pain capture the most common somatic diagnosis among sickness absent, e.g. musculoskeletal diseases. The measure somatic disease covered severe diagnoses such as myocardial infarction or diabetes, but is not an all-encompassing measure of somatic diagnoses, however the access to registered in-patient care made it possible to control for those with ill health that required in-patient care for shorter or longer periods during 2002, like tumors, 
Table 3 The association between short-term sick leave and long-term sick leave, disability pension and unemployment

\begin{tabular}{|c|c|c|c|c|c|}
\hline \multirow[t]{2}{*}{ Regression model } & \multirow[b]{2}{*}{$\begin{array}{c}\text { Short-term } \\
\text { sick-leave spells (STSL) }\end{array}$} & \multirow{2}{*}{$\begin{array}{c}\text { Sick leave }>30 \text { days in } 2007 \\
(\mathrm{n}=582)\end{array}$} & \multirow{2}{*}{$\begin{array}{c}\text { Disability pension in } 2007 \\
(\mathrm{n}=109)\end{array}$} & \multirow{2}{*}{$\begin{array}{l}\text { Unemployment in } 2006 \\
\leq 180 \text { days }(n=343) \\
\text { OR }(95 \% \mathrm{Cl})\end{array}$} & \multirow{2}{*}{$\begin{array}{l}\text { Unemployment in } 2006 \\
>180 \text { days }(n=103)\end{array}$} \\
\hline & & & & & \\
\hline \multirow[t]{3}{*}{ Crude } & No STSL & 1.00 & 1.00 & 1.00 & 1.00 \\
\hline & Low STSL & $1.40(1.15-1.70)$ & $0.72(0.46-1.12)$ & $1.10(0.86-1.43)$ & $1.10(0.73-1.68)$ \\
\hline & High STSL & $2.00(1.62-2.46)$ & $0.72(0.42-1.24)$ & $1.76(1.35-2.29)$ & $0.54(0.28-1.04)$ \\
\hline \multirow{3}{*}{$\begin{array}{l}\text { Model } 1 \text { (M1): Short- term sick leave adjusted for } \\
\text { socio-demographic factors }\end{array}$} & No STSL & 1.00 & 1.00 & 1.00 & 1.00 \\
\hline & Low STSL & $1.48(1.21-1.81)$ & $0.81(0.51-1.28)$ & $1.01(0.77-1.31)$ & $1.34(0.86-2.07)$ \\
\hline & High STSL & $2.27(1.81-2.84)$ & $1.08(0.62-1.90)$ & $1.33(1.00-1.76)$ & $0.70(0.35-1.42)$ \\
\hline \multirow[t]{3}{*}{ Model 2: M1 and self-rated health (SRH) } & No STSL & 1.00 & 1.00 & 1.00 & 1.00 \\
\hline & Low STSL & $1.47(1.20-1.81)$ & $0.75(0.47-1.19)$ & $1.01(0.78-1.32)$ & $1.32(0.85-2.06)$ \\
\hline & High STSL & $2.16(1.72-2.72)$ & $0.85(0.48-1.50)$ & $1.34(1.01-1.78)$ & $0.65(0.32-1.33)$ \\
\hline \multirow[t]{3}{*}{ Model 3: M1 and limiting longstanding illness (LLSI) } & No STSL & 1.00 & 1.00 & 1.00 & 1.00 \\
\hline & LOW STSL & $1.48(1.21-1.82)$ & $0.81(0.51-1.29)$ & $0.99(0.76-1.29)$ & $1.34(0.86-2.07)$ \\
\hline & High STSL & $2.16(1.72-2.71)$ & $0.93(0.53-1.64)$ & $1.32(0.99-1.75)$ & $0.68(0.33-1.37)$ \\
\hline \multirow[t]{3}{*}{ Model 4: M1 and mental wellbeing (GHQ12) } & No STSL & 1.00 & 1.00 & 1.00 & 1.00 \\
\hline & LOW STSL & $1.51(1.22-1.85)$ & $0.78(0.49-1.23)$ & $1.01(0.77-1.31)$ & $1.33(0.86-2.08)$ \\
\hline & High STSL & $2.29(1.82-2.87)$ & $1.02(0.58-1.80)$ & $1.25(0.93-1.67)$ & $0.60(0.29-1.25)$ \\
\hline \multirow[t]{3}{*}{ Model 5: M1 and musculoskeletal pain } & No STSL & 1.00 & 1.00 & 1.00 & 1.00 \\
\hline & LoW STSL & $1.47(1.19-1.80)$ & $0.76(0.48-1.21)$ & $1.01(0.77-1.31)$ & $1.31(0.84-2.03)$ \\
\hline & High STSL & $2.18(1.74-2.73)$ & $0.94(0.54-1.65)$ & $1.34(1.01-1.78)$ & $0.66(0.33-1.34)$ \\
\hline \multirow[t]{3}{*}{ Model 5: M1 and somatic disease } & No STSL & 1.00 & 1.00 & 1.00 & 1.00 \\
\hline & LoW STSL & $1.47(1.20-1.80)$ & $0.81(0.52-1.29)$ & $0.99(0.76-1.29)$ & $1.37(0.88-2.13)$ \\
\hline & High STSL & $2.24(1.78-2.81)$ & $1.07(0.61-1.88)$ & $1.34(1.01-1.78)$ & $0.72(0.36-1.46)$ \\
\hline \multirow[t]{3}{*}{ Model 7: M1 and in-patient care in 2002} & No STSL & 1.00 & 1.00 & 1.00 & 1.00 \\
\hline & LOW STSL & $1.47(1.20-1.80)$ & $0.78(0.50-1.24)$ & $1.00(0.77-1.30)$ & $1.35(0.87-2.09)$ \\
\hline & High STSL & $2.26(1.80-2.83)$ & $1.07(0.61-1.87)$ & $1.32(1.00-1.76)$ & $0.71(0.35-1.43)$ \\
\hline \multirow{3}{*}{$\begin{array}{l}\text { Model 8: M1 and GHQ12, SRH, LLSI, musculoskeletal } \\
\text { pain, somatic disease, in-patient care in } 2002\end{array}$} & No STSL & 1.00 & 1.00 & 1.00 & 1.00 \\
\hline & LOW STSL & $1.49(1.21-1.85)$ & $0.73(0.45-1.18)$ & $0.98(0.75-1.29)$ & $1.37(0.87-2.14)$ \\
\hline & High STSL & $2.11(1.67-2.67)$ & $0.74(0.42-1.33)$ & $1.29(0.97-1.74)$ & $0.56(0.26-1.18)$ \\
\hline
\end{tabular}

Odds ratios (OR) of the outcomes, (with 95\% confidence interval (CI)) among individuals with high (> one sick-leave spell), low (one sick-leave spell) and no short-term sick leave (STSL). Crude OR are shown, followed by seven multivariate models adjusted for health status and socio-demographic factors. 
psychiatric diseases, and coronary heart diseases. Hence, the analyses were adjusted for both self-reported and register data on diseases and health conditions. Nevertheless, it is not possible to fully discriminate between the consequences of sick leave and the ill-health as we cannot link the health status with each specific sick-leave spell. Despite this shortcoming, we believe that this study has a major advantage compared to several previous studies of the consequences of sick leave [32,33], in its adjustments for both self-reported and registered ill health.

Previous studies indicate that adverse work conditions and smoking are risk factors for disability pension [25-28]. Since these risk factors are likely to have their effect on disability pension through illness and sick leave, we have not considered them as confounders in our study.

One weakness in our study is the lack of register data on exposure, which implies an inexact exposure measurement and may imply recall bias and risk of response bias due to social desirability. The registers of sick leave in Sweden do not have valid data on the first 14 days of sick leave, since the 14 first days of sick leave are compensated by the employer and hence not included in the register held by the Swedish National Social Insurance Agency. Data on exposure to STSL were thus based on self-reported survey data. However, studies on the validity and reliability of register data and self-reported data on sick leave have not shown any significant differences between these two types of information [42-44]. The lack of register data also implies that the outcome long-term sick leave will only include individuals with sick-leave spells of at least 15 days, since these are the ones registered by the Swedish National Social Insurance Agency. Unfortunately, no other register data on the outcome long-term sick leave is available. If differential, this misclassification is likely to be more common among the exposed group, which would underestimate the odds ratios of long-term sick leave.

STSL can been seen as a coping strategy to prevent later long-term sick leave [45], or as an indicator of an underlying severe disease [41]. In this study, those with chronic or severe disease, recognized by long-term sick leave, in-patient care, or disability pension the year before the short-term absence, were excluded from the study group. Hence, the study population was a "healthy population", and most likely their subsequent ill health was either of short-lasting nature, or the beginning of a potential chronic, but not yet medically diagnosed, health condition. However, as mentioned above, to successfully investigate if a pathway exists from STSL, via long-term sick leave, to long-term labor-market exclusion, a longer follow up period than five years is likely to be needed. From our results we cannot determine through which mechanisms STSL affect long-term sick leave. Possible mediators between short-term and longterm sick leave remain for future studies to explore.

\section{Conclusions}

Short-term sick leave increased the odds ratio for future long-term sick leave, when adjusting for several measures of health status. This may imply that short-term sick leave has social and health-related consequences beyond the effects of the underlying ill health it reflects. The results point to the importance for workplaces to pay attention to employees' short-term sick leave in order to prevent subsequent long-term sick leave and to work with employee groups with high short-term sick leave in order to explore ways to reduce possible negative consequences. The results, however, showed no increased risk for disability pension or for longer unemployment.

\section{Competing interests}

The authors declare no competing interests.

\section{Authors' contributions}

$\mathrm{JM}$ and $\mathrm{CL}$ conceived the study idea. $\mathrm{HH}$ and MM performed the statistical analyses. All authors participated in the design and coordination of the study, the interpretation of the results, and drafted the manuscript. All authors read and approved the final manuscript.

\section{Acknowledgements}

This study was financially supported by grants from AFA Insurance (grant number: DNR090247).

The funding body did not have any role in design, data collection, analysis, and interpretation of data; or in the writing of the manuscript; or in the decision to submit the manuscript for publication.

\section{Author details}

'Department of Public Health Sciences, Karolinska Institutet, Stockholm, Sweden. ${ }^{2}$ Department of Clinical Neuroscience, Karolinska Institutet, Stockholm, Sweden. ${ }^{3}$ Uppsala Clinical Research Center, Uppsala University Hospital, Uppsala, Sweden.

Received: 13 December 2011 Accepted: 5 October 2012 Published: 10 October 2012

References

1. Kivimaki M, Head J, Ferrie JE, Shipley MJ, Vahtera J, Marmot MG: Sickness absence as a global measure of health: evidence from mortality in the Whitehall II prospective cohort study. BMJ 2003, 327(7411):364.

2. Kivimaki $M$, Head J, Ferrie JE, Singh-Manoux A, Westerlund H, Vahtera J, Leclerc A, Melchior M, Chevalier A, Alexanderson K, et al: Sickness absence as a prognostic marker for common chronic conditions: analysis of mortality in the GAZEL study. Occup Environ Med 2008, 65(12):820-826.

3. Marmot M, Feeney A, Shipley M, North F, Syme SL: Sickness absence as a measure of health status and functioning: from the UK Whitehall II study. J Epidemiol Community Health 1995, 49(2):124-130.

4. Alexanderson K: Research on sickness absence and disability pension. In Urbanisation and Health - New challenges $i$ health promotion and prevention. Edited by Tellnes G. Oslo: unipubforlag; 2005:306-315.

5. Borg K, Hensing G, Alexanderson K: Predictive factors for disability pension. An 11-year follow-up of young persons on sick leave due to neck, shoulder, or back diagnoses. Scand J Publ Health 2001, 29(2):104-112.

6. Bratberg E, Gjesdal S, Maeland J: Sickness absence with psychiatric diagnoses: individual and contextual predictors of permanent disability. Health Place 2009, 15(1):308-314. 
7. Gjesdal S, Bratberg E: Diagnosis and duration of sickness absence as predictors for disability pension: Results from a three-year, multiregister based and prospective study. Scand J Publ Health 2003, 31:246-254.

8. Gjesdal S, Ringdal P, Haug K, Maeland JG: Predictors of disability pension in long-term sickness absence: results from a population-based and prospective study in Norway 1994-1999. Eur J Publ Health 2004, 14 (4):398-405.

9. Kivimäki M, Ferrie J, Hagberg J, Head J, Westerlund H, Vahtera J, Alexanderson K: Sick leave as a risk marker of disability pension: 11-year prospective cohort study in Sweden. J Epidemiol Community Health 2007 61:915-920.

10. Kivimäki M, Forma P, Wikström J, Halmeenmäki T, Pentti J, Elovainio M, Vahatera J: Sickness absence as a risk marker of future disability pension: the 10-town study. J Epidemiol Community Health 2003, 58:710-711.

11. Virtanen $M$, Kivimaki $M$, Vahtera J, Elovainio $M$, Sund $R$, Virtanen P, Ferrie JE: Sickness absence as a risk factor for job termination, unemployment, and disability pension among temporary and permanent employees. Occup Environ Med 2006, 63(3):212-217.

12. Borg K, Hensing G, Alexanderson K: Risk factors for disability pension over eleven years in a cohort of young persons initially sick-listed with low back, neck, or shoulder diagnoses: an analysis using the Cox-regression model with time-dependent covariates. Scand J Publ Health 2004, 32:272-278.

13. Gjesdal S, Bratberg E: The role of gender in long-term sickness absence and transition to permanent disability benefits. Eur J Publ Health 2002, 12:180-186

14. Gjesdal S, Bratberg E, Mæland JG: Musculoskeletal Impairments in the Norwegian Working Population: The Prognostic Role of Diagnoses and Socioeconomic Status: A Prospective Study of Sickness Absence and Transition to Disability Pension. Spine 2009, 34(14):1519-1525. doi:1510.1097/BRS.1510b1013e3181a1518dee1513.

15. Kivimaki M, Forma P, Wikstrom J, Halmeenmaki T, Pentti J, Elovainio M Vahtera J: Sickness absence as a risk marker of future disability pension: the 10-town study. J Epidemiol Community Health 2004, 58(8):710-711.

16. Labriola M, Lund T: Self-reported sickness absence as a risk marker of future disability pension. Prospective findings from the DWECS/DREAM study 1990-2004. Int J Med Sci 2007, 4:153-158.

17. Lund T, Kivimaki M, Labriola M, Villadsen E, Christensen KB: Using administrative sickness absence data as a marker of future disability pension: the prospective DREAM study of Danish private sector employees. Occup Environ Med 2008, 65(1):28-31.

18. Koopmans P, Roelen C, Groothoff J: Risk of future sickness absence in frequent and long-term absentees. Occup Med 2008, 58:268-274.

19. Bryngelson A: Long-term sickness absence and social exclusion. Scand J Publ Health 2009, 37(8):839-845.

20. Dekkers-Sanchez PM, Hoving JL, Sluiter JK, Frings-Dresen MH: Factors associated with long-term sick leave in sick-listed employees: a systematic review. Occup Environ Med 2008, 65(3):153-157.

21. Allebeck P, Mastekaasa A: Risk factors for sick leave - general studies. Scand J Publ Health 2004, 32(Supplement 63):49-108.

22. Karlsson N, Borg K, Carstensen J, Hensing G, Alexanderson K: Risk of disability pension in relation to sex and age in a Swedish county 1985-1996; a 12-year prospective cohort study. Work 2006, 27:173-179.

23. Karlsson N, Carstensen J, Gjesdal S, Alexanderson K: Risk factors for disability pension in a population-based cohort of men and women on long-term sick leave in Sweden. Eur J Publ Health 2008, 18(3):224-231.

24. Leijon M, Hensing $G$, Alexanderson $\mathrm{K}$ : Gender trends in sick-listing with musculoskeletal symptoms in a Swedish county during a period of rapid increase in sickness absence. Scand J Soc Med 1998, 26(3):204-213.

25. Karpansalo M, Manninen P, Lakka TA, Kauhanen J, Rauramaa R, Salonen JT: Physical workload and risk of early retirement: prospective populationbased study among middle-aged men. J Occup Environ Med 2002, 44 (10):930-939.

26. Krause N, Lynch J, Kaplan GA, Cohen RD, Goldberg DE, Salonen JT: Predictors of disability retirement. Scand J Work Environ Health 1997, 23 (6):403-413.

27. Vahtera J, Laine S, Virtanen M, Oksanen T, Koskinen A, Pentti J, Kivimaki M: Employee control over working times and risk of cause-specific disability pension: the Finnish Public Sector Study. Occup Environ Med 2010, 67 (7):479-485
28. Laine S, Gimeno D, Virtanen M, Oksanen T, Vahtera J, Elovainio M, Koskinen A, Pentti J, Kivimaki M: Job strain as a predictor of disability pension: the Finnish Public Sector Study. J Epidemiol Community Health 2009, 63(1):24-30.

29. Koopmans P, Roelen C, Groothoff J: Frequent and long-term absence as a risk factor for work disability and job termination among employees in the private sector. Occup Environ Med 2008, 65:494-499.

30. Roelen CA, Koopmans PC, Schreuder JA, Anema JR, van der Beek AJ: The history of registered sickness absence predicts future sickness absence. Occup Med (Lond) 2011, 61(2):96-101.

31. Wallman T, Wedel H, Palmer E, Rosengren A, Johansson S, Eriksson H, Svärdsudd K: Sick-leave track record and other potential predictors of a disability pension. A population based study of 8,218 men and women followed for 16 years. BMC Publ Health 2009, (9):104

32. Sieurin $L$, Josephson M, Vingard E: Positive and negative consequences of sick leave for the individual, with special focus on part-time sick leave. Scand J Publ Health 2009, 37(1):50-56.

33. Vingard E, Alexanderson K, Norlund A: Chapter 9. Consequences of being on sick leave. Scand J Publ Health 2004, 32:207-215.

34. Swedish National Insurance Act (1962:381). http://www.riksdagen.se/ webbnav/index.aspx?nid=3911\&bet=1962:381.

35. Swedish Sick Pay Act (1991:1074). http://www.riksdagen.se/webbnav/index. aspx?nid=3911\&bet=1991:1047.

36. SCB: Socioekonomisk indelning (SEI) (Socioeconomic classification) (In Swedish), Statistics Sweden. 1982

37. Eriksson I, Unden AL, Elofsson S: Self-rated health. Comparisons between three different measures. Results from a population study. Int J Epidemiol 2001, 30(2):326-333.

38. Unden AL, Elofsson S: Self-rated health in a European perspective. Swedish council for planning and coordination of research; 2000.

39. Goldberg DP GR, Sartorius N, Ustun TB, Piccinelli M, Gureje O, Rutter C: The validity of two versions of GHQ in the WHO study of mental illness in general health care. Psychol Med 1997, 27(1):191-197.

40. Wadman C, Bostrom G, Karlsson A-S: Health on equal terms? Results from the 2006 Swedish National Public Health Survey. Östersund, Sweden: Swedish National Institute of Public Health; 2008.

41. Blank N, Diderichsen F: Short-term and long-term sick-leave in Sweden: relationships with social circumstances, work conditions and gender. Scand J Soc Med 1995, 23:265-272.

42. Ferrie JE, Kivimaki M, Head J, Shipley MJ, Vahtera J, Marmot MG: A comparison of self-reported sickness absence with absences recorded in employers' registers: evidence from the Whitehall II study. Occup Environ Med 2005, 62(2):74-79.

43. Fredriksson $\mathrm{K}$, Toomingas A, Torgen M, Thorbjornsson CB, Kilbom A: Validity and reliability of self-reported retrospectively collected data on sick leave related to musculoskeletal diseases. Scand J Work Environ Health 1998, 24(5):425-431.

44. van Poppel MNM, de Vet HC, Koes BW, Smid T, Bouter LM: Measuring sick leave: a comparison of self-reported data on sick leave and data from company records. Occup Med 2002, 52(8):485-490.

45. Kristensen TS: Sickness absence and work strain among Danish slaughterhouse workers: An analysis of absence from work regarded as coping behaviour. Soc Sci Med 1991, 32(1):15-27.

\section{doi:10.1186/1471-2458-12-861}

Cite this article as: Hultin et al:: Short-term sick leave and future risk of sickness absence and unemployment - the impact of health status. BMC Public Health 2012 12:861. 